\title{
Impact on IVF outcome following Pre-IVF hysteroscopy and endometrial scratching
}

\author{
K. Jayakrishnan ${ }^{1}$, N. Maya², Divya Nambiar ${ }^{3}$ \\ ${ }^{1}$ Dr K. Jayakrishnan, Chief Consultant in Reproductive Medicine, ${ }^{2}$ Dr. N. Maya, Fellow in Reproductive Medicine. ${ }^{3}$ Dr. \\ Divya Nambiar, Consultant in Reproductive Medicine; all are affiliated with KJK Hospital Trivandrum, India
}

Address for Correspondence: Dr. N. Maya, Fellow in Reproductive Medicine, KJK Hospital, Trivandrum, India

\begin{abstract}
Background: Transvaginal ultrasonography and hysteroscopy are the tools to assess the inner architecture of the uterus. In India as such very few studies were conducted to see the effect of endometrial injury on the pregnancy outcome, so the current study was conducted to assess the efficacy of hysteroscopy in identifying the uterine pathologies and to assess the pregnancy rate following the endometrial scratching. Methods: A prospective cohort study was conducted during June 2012 to may 2015 at KJK Hospital, Trivandrum. All patients undergoing IVF in the said duration are scheduled for Pre IVF Hysteroscopy prior to the onset of periods. All the study population had undergone a transvaginal USG and hysteroscopy. Half of the study population $(n=175)$ had underwent endometrial scratching and the occurrence of clinical pregnancy was compared among the group who had not undergone the endometrial scratching. Results: The sensitivity $(100 \%)$ and specificity (85\%) was much higher for hysteroscopy when compared with USG. There was a statistically significant difference in the occurrence of clinical pregnancy among the patients for whom endometrial scratching done when compared to those who had not undergone endometrial scratching $(\mathrm{p}<.0001)$. Conclusions: Through hysteroscopy, the intrauterine pathologies and structural uterine abnormalities that may be responsible for the failure of IVF can be detected and treated, resulting in improved pregnancy rates and the clinical pregnancy and implantation rates significantly increase after endometrial scratching in same cycle in patients with good-quality embryos.
\end{abstract}

Keywords: Endometrial Scratching, IVF, Hysteroscopy

\section{Introduction}

Among the in vitro fertilization (IVF) and intracytoplasmic sperm injection (ICSI), the implantation rate per embryo transferred usually does not exceed $30 \%$, although higher rates with the use of blastocysts have been reported, depending on female age $[1,2]$.

Embryo quality, good conditions of the uterine environment, a skillful IVF laboratory and embryo transfer are essential in order to achieve a pregnancy in IVF. Unsuspected uterine cavity abnormalities, such as endometrial polyps, small submucous myomas, adhesions and septa are considered to lessen the chances to conceive through IVF [3].

Hysterosalpingography, transvaginal ultrasonography, saline infusion sonography and hysteroscopy are the various measures to assess the inner architecture of the

Manuscript Received: $14^{\text {th }}$ Oct 2015

Reviewed: $26^{\text {th }}$ Nov 2015

Author Corrected: $30^{\text {th }}$ Nov 2015

Accepted for Publication: $4^{\text {th }}$ Jan 2016

Obsgyne Review: Journal of Obstetrics and Gynecology $P$ a g e uterus [4]. Hysteroscopy is considered to be the gold standard; whereas, the World Health Organization (WHO) recommends only hysterosalpingography (HSG) [5] The explanation for this discrepancy is that HSG provides information on tubal patency or blockage.

Office hysteroscopy is only recommended by the WHO when clinical or complementary exams suggest intrauterine abnormality [6]. Nevertheless, many specialists feel that hysteroscopy is a more accurate tool because of the high false-positive and false negative rates of intrauterine abnormality with HSG[7-9] because of that many specialists use hysteroscopy as a first-line routine exam for infertility patients regardless of guidelines. But the validity of hysteroscopy is limited in the diagnosis of endometritis and endometrial hyperplasia [5].

The prevalence of minor intrauterine abnormalities identified at hysteroscopy in cases with a normal

Available online at: www.medresearch.in 21 | 


\section{Original Research Article}

transvaginal sonography has been recorded as very high (40\%). Diagnosing and treating such pathologies prior to initiating IVF/ICSI is highly recommended to have a positive outcome [5].

Implantation failure is presently the major barrier in human fertility and it is attributed to the failure of the uterus to acquire receptivity. For transition into a receptive uterus, it needs the following things to occur, cellular changes in the endometrium and the modulated expression of different cytokines, growth factors, transcription factors, and prostaglandins. Embryo implantation is associated with an active Th1 inflammatory response while a Th2-humoral inflammation is required for pregnancy maintenance. Inspite of all these measures, repeated implantation failure continues to be a big challenge ahead [10].

Barash et al [11] were the first to study the effect of endometrial scratching on the pregnancy outcome.[12] They demonstrated a significant doubling of the implantation, clinical pregnancy, and live birth rates in patients who underwent endometrial scraping in the cycle immediately preceding the IVF cycle. They hypothesized that the injury to the endometrium could lead to a massive secretion of growth factors and cytokines during the process of wound healing which would help the embryo to get implanted.

\section{Aims and Objectives}

1. To assess the incidence of undiagnosed intrauterine pathology based on pre IVF Hysteroscopy findings and compare it with the findings of USG.

2. To assess the pregnancy rate following the endometrial scratching.

Methodology: A prospective cohort study was conducted during June 2012 to May 2015 at KJK Hospital, Trivandrum. All patients undergoing IVF in the said duration are scheduled for Pre IVF
Hysteroscopy prior to the onset of periods. A total of 362 women were included in the study.

Technique: All women in whom hysteroscopy was done were informed about the technique and the potential risks in the form of a written consent. The selected women underwent the procedure of hysteroscopy under general anesthesia in the lithotomy position. A rigid hysteroscope was put into the uterine cavity under visual control after cervical dilatation of five to nine millimeters; normal saline was used as the distension medium, keeping the uterine pressure between 100 and $150 \mathrm{~mm}$ of mercury.

Intrauterine lesions, such as, synechiae, polyps, submucosal myomas, septae, and so on, were treated with scissors and resectoscope. Every hysteroscopy was followed by endometrial scratching with the scope itself and the material obtained was sent for histopathological examination.

In order to assess the impact of endometrial scratching, it was done on $50 \%$ of the study population.

Protocol of stimulation in subsequent IVF/ICSI attempts: Depending upon the diagnosis and the procedure done, the women were either stimulated immediately or after some period for IVF/ICSI cycle. The women were downregulated with oral contraceptive pills and Gonadotropin-releasing hormone $(\mathrm{GnRH})$ analogues. Injection HMG (Human Menopausal Gonadotrophin) was started from the second day of menses and simultaneous follicular monitoring was done from the sixth day. Injection HCG (Human Chorionic Gonadotrophin) was given when a minimum of three leading follicles were $16.18 \mathrm{~mm}$ size. Thirty-six hours later oocyte retrieval was performed followed by IVF/ICSI, and then the embryo transfer. Data entry and analysis was performed in SPSS version 17.0.

\section{Results}

Among the 362 women 15 were excluded from the study as embryo transfer was not done on them and so the sample size was 347. The demographic parameters among the study population shows that the mean age of the mothers was 36.25 years and their mean duration of marriage life was 5.75 years. For majority of the study population it was the $2^{\text {nd }}$ attempt for IVF (Table 1). The uterine pathologies which were picked up hysteroscopy was almost 4 times more than the uterine anomalies reported by USG. The sensitivity (100\%) and specificity (85\%) was much higher for hysteroscopy when compared with USG (Table 2).

The most common pathology detected by hysteroscopy among the study population was polyp followed by adhesions. All the pathologies detected by hysteroscopy were corrected by various interventions. The various pathologies detected and the interventions done through hysteroscopy were highlighted under table 3. 
Original Research Article

Table 1 : Mean and SD of the demographic parameters among the study population

\begin{tabular}{|l|l|l|}
\hline Demographic parameter & Mean & SD \\
\hline Age of mother (in years) & 36.25 & 2.3 \\
\hline Duration of married life (in years) & 5.75 & 1.4 \\
\hline Number of attempts (IVF) & 1.25 & 0.35 \\
\hline
\end{tabular}

Table 2: Comparison of the findings between hysteroscopy and ultrasonogram

\begin{tabular}{|l|l|l|l|}
\hline Findings & USG & Hysteroscopy & \multirow{2}{*}{ P value (Chisquare test) } \\
\hline Pathology detected & 15 & 64 & \\
\hline No pathology & 332 & 283 & \\
\hline Total & 347 & 347 & \\
\hline $\begin{array}{l}\text { Sensitivity of } \\
\text { Hysteroscopy }\end{array}$ & $100 \%$ & \multicolumn{2}{|l}{} \\
\cline { 1 - 2 } $\begin{array}{l}\text { Specificity of } \\
\text { hysteroscopy }\end{array}$ & $85 \%$ & \multicolumn{2}{|l}{} \\
\cline { 1 - 2 }
\end{tabular}

Table 3 : Distribution of the study population based on the type of pathologies detected by hysteroscopy and the interventions done

\begin{tabular}{|c|c|c|c|c|c|}
\hline $\begin{array}{l}\text { Type of } \\
\text { pathologies }\end{array}$ & Number & Percentage & $\begin{array}{l}\text { Type of } \\
\text { interventions }\end{array}$ & Number & Percentage \\
\hline Polyp & 37 & $57.8 \%$ & Polypectomy & 30 & $58.8 \%$ \\
\hline Adhesions & 6 & $9.3 \%$ & Biopsy & 7 & $13.7 \%$ \\
\hline Arcuate & 6 & $9.3 \%$ & Adhesiolysis & 6 & $11.7 \%$ \\
\hline Partial septum & 6 & $9.3 \%$ & $\begin{array}{l}\text { Septal } \\
\text { resection }\end{array}$ & 6 & $11.7 \%$ \\
\hline Atrophic & 2 & $3.1 \%$ & SMF resection & 2 & $3.9 \%$ \\
\hline $\begin{array}{l}\text { Bulge in anterior } \\
\text { wall }\end{array}$ & 2 & $3.1 \%$ & Total & 51 & $100 \%$ \\
\hline SMF & 2 & $3.1 \%$ & & & \\
\hline $\begin{array}{l}\text { Thick } \\
\text { endometrium }\end{array}$ & 2 & $3.1 \%$ & & & \\
\hline Bicornuate & 1 & $1.5 \%$ & & & \\
\hline Total & 64 & $100 \%$ & & & \\
\hline
\end{tabular}

Table 4: Endometrial scratching and the impact of pregnancy

\begin{tabular}{|l|l|l|l|}
\hline Endometrial scratching & $\begin{array}{l}\text { Urine pregnancy test } \\
\text { positive }\end{array}$ & $\begin{array}{l}\text { Urine pregnancy test } \\
\text { negative }\end{array}$ & \multirow{2}{*}{ P value (Chi square test) } \\
\hline Done (n=175) & $106(60.5 \%)$ & $69(39.4 \%)$ & \multirow{2}{*}{$<.00001$} \\
\cline { 1 - 2 } Not done $(\mathbf{n}=\mathbf{1 7 2})$ & $16(9.3 \%)$ & $156(90.6 \%)$ & \\
\hline Total & 122 & 225 & \\
\hline
\end{tabular}

For assessing the impact of endometrial scratching the study population were divided into two groups for one group $(n=175)$ the scratching was done and for the other group the scratching was not done $(n=172)$. Among the patients for whom the scratching was done, in the follow up 106 had clinical pregnancy which was confirmed by urine pregnancy test. There was a statistically significant difference in the occurrence of

Obsgyne Review: Journal of Obstetrics and Gynecology $P$ a g e clinical pregnancy among the patients for whom endometrial scratching was done when compared to those who had not undergone endometrial scratching $(\mathrm{p}<.0001)$ (Table 4). 


\section{Discussions}

Several studies have compared the diagnostic values of transvaginal ultrasonography and hysteroscopy in diagnosing uterine pathologies. However, distributions of the uterine conditions vary in those samples. A recent study by Vitner et al. found higher sensitivity and specificity for hysteroscopy in diagnosing uterine myomas, when compared to TVU; whereas, TVU had higher sensitivity for diagnosing the retained products of conception [13] On the other hand, they failed to find a statistical difference between the two methods for the diagnosis of the polyps. In that study, the frequencies of endometrial polyps, uterine myomas and retained products of conception were close to each other: 27,32 and $38 \%$ of the sample population, respectively. In contrast, uterine polyps comprised a great proportion of the patient sample in this study $(n=37,57.8 \%)$, and we found better sensitivity and specificity for diagnosing polyps with hysteroscopy.

Similar to the findings in this study, Mukhopadhayay et al. found a high sensitivity (71.4\%) and specificity (100.0\%) for hysteroscopy for diagnosing polyps [14] with strong agreement with biopsy findings $(\mathrm{k}=0.81)$. Soguktas et al. found better diagnostic value for hysteroscopy when compared to both saline infusion sonography and transvaginal ultrasonography in detecting uterine polyps; however, for detection of any uterine pathology, hysteroscopy and saline infusion sonography had similar efficacy but better than transvaginal ultrasonography [15] Similarly, Mathlouthi et al [16] and Yela et al [17] found diagnostic values in favor of hysteroscopy for the diagnosis of uterine pathologies. In the study by Yela et al., the specificity of TVU in particular was remarkably low $(7.4 \%)$ for the detection of uterine disease [17] Kasraeian et al., examined the diagnostic value of transvaginal ultrasonography in non-bleeding postmenopausal women and found only moderate accuracy to diagnose uterine pathologies [18].

The place of routine hysteroscopy in the management of infertile women without other diagnosed or doubtful intrauterine pathologies is still a matter of debate [19] The two main problems that argue against the case of hysteroscopy are: first, it is an invasive procedure, and second, there is still an ongoing debate about the real significance of the observed intrauterine pathology on fertility [20]. Nevertheless, in a study by Shoker et al., it was suggested that $26 \%$ of the patients with normal hysterosalpingography were with abnormal hysteroscopic findings [21].

\section{Original Research Article}

The impact of polyps on infertility is mainly dependent on their size and location. A prospective randomized study of the impact of polyps on an IVF program, by Lass et al.[22] concluded that small endometrial polyps (less than two centimeters) do not decrease the pregnancy rate after IVF, but a trend toward increased pregnancy loss exists.

The available data on the role of submucous myomas in infertility and the impact of hysteroscopic myomectomy on pregnancy outcome shows encouraging results. Authors have reported clinical pregnancy rates ranging from $31 \%$ to $77 \%$ post myomectomy. Women who had myomectomies for myomas more than two centimeters had significantly higher pregnancy and live birth rates than women in whom myomectomy was not done [23].

The role of hysteroscopic septum resection in patients with septate uterus has also been studied extensively [24] A meta analysis of retrospective data comparing pregnancy outcome before and after hysteroscopic septoplasty indicated a marked improvement after surgery, in increasing the pregnancy rate and decreasing the miscarriage rate.

The local injury of the endometrium in IVF patients substantially increased the incidence of pregnancy and more than doubled the rate of live birth rates. Moreover, this protocol that increased the implantation rate did not enhance the risk of multiple pregnancy.

The evidence is strongly in favour of inducing local endometrial injury in the preceding cycle of ovarian stimulation to improve pregnancy outcomes in women with unexplained RIF. However, large randomized studies are required before iatrogenic induction of local endometrial injury can be warranted in routine clinical practice.

Some women undergoing IVF treatment fail to conceive despite several attempts with good-quality embryos and no identifiable reason. We call this "recurrent implantation failure" (RIF) where the embryo fails to embed or implant within the lining of the womb. Studies have shown that inducing injury to the lining of the womb in the cycle before starting ovarian stimulation for IVF can help improve the chances of achieving pregnancy. Injury can be induced by either scratching the lining of the womb with biopsy cannula or through hysteroscopy. Inducing injury is $70 \%$ more likely to result in a clinical pregnancy as opposed to no treatment. 


\section{Original Research Article}

Furthermore, scratching of the lining was 2-times more likely to result in a clinical pregnancy compared with hysteroscopic evaluation of the uterus. In women with RIF, inducing local injury to the womb lining in the cycle prior to starting ovarian stimulation for IVF can improve pregnancy outcomes [25] So, endometrial scratching in a systematic manner by non traumatizing instrument is associated with higher implantation potential.

\section{Conclusions}

The role of hysteroscopy in patients undergoing IVF seems to be vital for patients in whom an IVF is being contemplated, for treatment of infertility. Intrauterine pathologies and structural uterine abnormalities that may be responsible for the failure of IVF can be detected and treated, resulting in improved pregnancy rates. The clinical pregnancy and implantation rates significantly increase after endometrial scratching in same cycle in patients with good-quality embryos. This phenomenon could be due to the injury-induced endometrial decidualization secondary to upregulation of genes encoding for locally acting mediators.

Conflict of interest: None declared.

Funding: Nil, Permission from IRB: Yes

\section{References}

1. Andersen AN, Goossens V, Ferraretti AP, Bhattacharya S, Felberbaum R, de Mouzon J, Nygren KG. Assisted reproductive technology in Europe, 2004: results generated from European registers by ESHRE. Hum Reprod. 2008 Apr;23(4):756-71. doi: 10.1093/humrep/den014. Epub 2008 Feb 14.

2. Stillman RJ, Richter KS, Banks NK, Graham JR. Elective single-embryo transfer: a 6-year progressive implementation of 784 single blast cyst transfers and the influence of payment method on patient choice. Fertil Steril. 2009 Dec;92(6):1895-906. doi: 10.1016/j.fertnstert.2008.09.023. Epub 2008 Oct 31.

3. Rogers PA, Milne BJ, Trounson AO. A model to show human uterine receptivity and embryo viability following ovarian stimulation for in vitro fertilization. $\mathrm{J}$ In Vitro Fert Embryo Transf. 1986 Apr;3(2):93-8.

4. Bozdag G, Aksan G, Esinler I, Yarali H. What is the role of office hysteroscopy in women with failed IVF cycles? Reprod Biomed Online. 2008 Sep;17(3):410-5.
5. Koskas M, Mergui JL, Yazbeck C, Uzan S, Nizard J. Office hysteroscopy for infertility: a series of 557 consecutive cases. Obstet Gynecol Int. 2010;2010:168096. doi: 10.1155/2010/168096. Epub 2010 Apr 14.

6. Brown SE, Coddington CC, Schnorr J, Toner JP, Gibbons W, Oehninger S. Evaluation of outpatient hysteroscopy, saline infusion hysterosonography, and hysterosalpingography in infertile women: a prospective, randomized study. Fertil Steril. 2000 Nov;74(5):1029-34.

7. Golan A, Eilat E, Ron-El R, Herman A, Soffer Y, Bukovsky I. Hysteroscopy is superior to hysterosalpingography in infertility investigation. Acta Obstet Gynecol Scand. 1996 Aug;75(7):654-6.

8. Roma Dalfó A, Ubeda B, Ubeda A, Monzón M, Rotger R, Ramos R, Palacio A. Diagnostic value of hysterosalpingography in the detection of intrauterine abnormalities: a comparison with hysteroscopy. AJR Am J Roentgenol. 2004 Nov;183(5):1405-9.

9. Firoozeh Ahmadi, Zohreh Rashidy, Hadieh Haghighi, Mohamadreza Akhoond, Maryam Niknejadi, Mandana Hemat, Mansour ShamsiPour, Uterine cavity assessment in infertile women: Sensitivity and specificity of three-dimensional Hysterosonography versus Hysteroscopy. Iran J Reprod Med. 2013 Dec; 11(12): 977-982.

10. Wael S. Nossair, Manal M. El Behery, Mohamed Al S. Farag. Endometrial Scratch-Suction and Implantation Failure. Open Journal of Obstetrics and Gynecology.2014.4.217-227 Published Online March 2014 in SciRes. http://www.scirp.org/journal/ojog http://dx.doi.org/10.4236/ojog.2014.45036

11. Barash, A., Dekel, N., Fieldust, S., Segal, I., Schechtman, E. and Granot, I. Local Injury to the Endometrium Doubles the Incidence of Successful Pregnancies in Patients Undergoing in Vitro Fertilization. Fertility and Sterility. 2003.June 79 (6) 1317-1322.

12. Granot I, Gnainsky Y, Dekel N. Endometrial inflammation and effect on implantation improvement and pregnancy outcome. Reproduction. 2012 Dec;144(6):661-8. doi: 10.1530/REP-12-0217. Epub 2012 Oct 1 


\section{Original Research Article}

13. Vitner D, Filmer S, Goldstein I, Khatib $\mathrm{N}$ and Weiner Z. A comparison between ultrasonography and hysteroscopy in the diagnosis of uterine pathology. Eur J Obstet Gynecol Reprod Biol 2013; 171(1): 143-145 doi: 10.1016/j.ejogrb.2013.08.024.

14. Mukhopadhayay S, Bhattacharyya SK, Ganguly RP, Patra KK, Bhattacharya $\mathrm{N}$ and Barman SC. Comparative evaluation of perimenopausal abnormal uterine bleeding by transvaginal sonography, hysteroscopy and endometrial biopsy. J Indian Med Assoc 2007; 105 (11): 624, 626, 628 passim.

15. Soguktas S, Cogendez E, Kayatas SE, Asoglu MR, Selcuk S and Ertekin A. Comparison of saline infusion sonohysterography and hysteroscopy in diagnosis of premenopausal women with abnormal uterine bleeding. Eur J Obstet Gynecol Reprod Biol 2012; March 161(1): 66-70 doi: 10.1016/j.ejogrb.2011.11.022.

16. Mathlouthi N, Slimani O, Ferchichi A, Ben Temime R, Makhlouf T, Attia L and Chachia A. Postmenopausal bleeding. Comparison between ultrasonography, hysteroscopy and histology results. Tunis Med 2013; Feb 91 (2) : 99-103

17. Yela DA, Ravacci SH, Monteiro IM, Pereira KC and Gabiatti JR. [Comparative study of transvaginal sonography and outpatient hysteroscopy for detection of pathologic endometrial lesions in postmenopausal women]. Rev Assoc Med Bras 2010 56(6): 711-14.

18. Kasraeian M, Asadi N, Ghaffarpasand F and Karimi AA. Value of transvaginal ultrasonography in endometrial evaluation of non-bleeding postmenopausal women. Climacteric 2011; 14 (1): 126-131.
19. De Placido G, Clarizia R, Cadente C, Castaldo G, Romano C, Mollo A, et al. Ongoing debate the real signip cance of the observed uterine pathology on fertility. Eur J Reprod Biol 2007;135 (2):83-7.

20. Crosignani PG, Rubin BL. Optimal use of infertility diagnostic tests and treatments: The ESHRE Capri Workshop Group. Hum Reprod 2000;March 15 (3):723-32.

21. Shokeir TA, Shalan HM, EI Shafei MN. Signib cance of endometrial polyps detected hysteroscopically in infertile women. J Obstet Gynecol 2004;April 30 (2):84-9.

22. Lass A, Williams G, Abusheikha N, Brinsden P. The effects of endometrial polyps on in virto fertilisation. J Assist Reprod Genet 1999. Sept 16 (8):410-5.

23. Pritts EA, Parker WH, Olive DL. Fibroids and Infertility: A systematic review of the evidence. Fertil Steril. 2009 Apr;91(4):1215-23. doi: 10.1016/j.fertnstert.2008.01.051. Epub 2008 Mar 12. Review.

24. Grimbizis GF, Camus M, Tarlatzis BC, Bontis JN, Devroey P. Clinica implications of uterine malformations and hysteroscopic treatment results. Hum Reprod Update 2001. Mar-Apr 7(2):161-74.

25. Potdar, N., Gelbaya, T. and Nardo, L.G. (2012) Endometrial Injury to Overcome Recurrent Embryo Implantation Failure: A Systematic Review and MetaAnalysis. Reproductive BioMedicine Online, 25, 561571. http://dx.doi.org/10.1016/j.rbmo.2012.08.005.

\section{How to cite this article?}

K. Jayakrishnan, N. Maya, Divya Nambiar. Impact on IVF outcome following Pre-IVF hysteroscopy and endometrial scratching . Obs Rev: J obstet Gynecol 2015;1(1):21-26. doi: 10.17511/joog.2015.i01.05. 